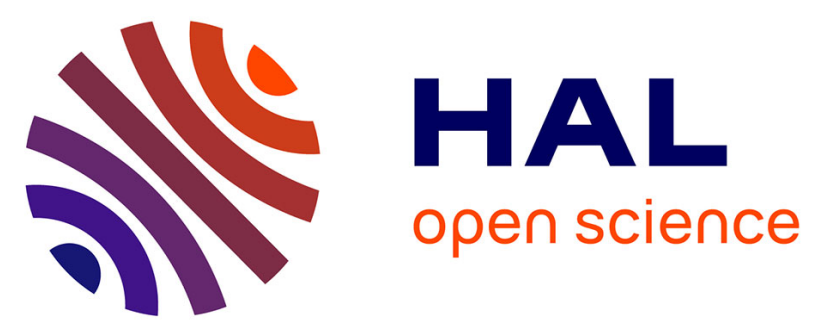

\title{
Solvothermal hydrodeoxygenation of hydroxymethylfurfural derived from biomass towards added value chemicals on $\mathrm{Ni} / \mathrm{TiO} 2$ catalysts
}

Martyna Przydacz, Marcin Jędrzejczyk, Magdalena Brzezińska, Jacek

Rogowski, Nicolas Keller, Agnieszka M Ruppert

\section{To cite this version:}

Martyna Przydacz, Marcin Jędrzejczyk, Magdalena Brzezińska, Jacek Rogowski, Nicolas Keller, et al.. Solvothermal hydrodeoxygenation of hydroxymethylfurfural derived from biomass towards added value chemicals on Ni/TiO2 catalysts. Journal of Supercritical Fluids, 2020, 163, pp.104827. 10.1016/j.supflu.2020.104827 . hal-03093310

\section{HAL Id: hal-03093310 https://hal.science/hal-03093310}

Submitted on 3 Jan 2021

HAL is a multi-disciplinary open access archive for the deposit and dissemination of scientific research documents, whether they are published or not. The documents may come from teaching and research institutions in France or abroad, or from public or private research centers.
L'archive ouverte pluridisciplinaire HAL, est destinée au dépôt et à la diffusion de documents scientifiques de niveau recherche, publiés ou non, émanant des établissements d'enseignement et de recherche français ou étrangers, des laboratoires publics ou privés. 
Solvothermal hydrodeoxygenation of hydroxymethylfurfural derived from biomass towards added value chemicals on $\mathrm{Ni} / \mathrm{TiO}_{2}$ catalysts

Martyna Przydacz ${ }^{1}$, Marcin Jędrzejczyk ${ }^{1}$, Magdalena Brzezińska ${ }^{1}$, Jacek Rogowski ${ }^{1}$, Nicolas Keller ${ }^{2}$, Agnieszka M. Ruppert ${ }^{1 *}$

1 Institute of General and Ecological Chemistry, Faculty of Chemistry, Lodz University of Technology ul. Zeromskiego 116, 90-924 Lodz (Poland)

E-mail:agnieszka.ruppert@p.lodz.pl

2 Institut de Chimie et Procédés pour l'Energie, l'Environnement et la Sante (ICPEES), CNRS ,University of Strasbourg 25 rue Becquerel, 67087, Strasbourg (France)

E-mail:nkeller@unistra.fr 


\section{Abstract}

Lignocellulosic biomass is one of the most abundant renewable source of commodity chemicals like hydroxymethylfurfural. Solvothermal hydrodeoxygenation of hydroxymethylfurfural towards value added chemicals was performed with a series of nickel based catalysts supported on different titania materials, ie. hydrothermally-prepared high aspect ratio and commercial $\mathrm{TiO}_{2}$ with different morphologies and crystallographic structures. The kind of titania strongly influenced the properties of the supported nickel nanoparticles, which allowed to tune the reaction selectivity towards specific products. Rutile-containing titania forced stronger Ni-Ti interaction, enhanced hydrogen adsorption, and formed larger Ni particles which resulted in high activity. Hydrothermally-prepared materials allowed to obtain selectively 2,5-bishydroxymethyltetrahydrofuran (biopolymer precursor) due a relatively small surface acidity and large Ni particles. By contrast, large surface area anatase with small nickel particles and small surface acidity allowed to selectively obtain 2,5-dimethylfuran (biofuel additive).

Keywords: hydrothermally prepared titania, $\mathrm{Ni} / \mathrm{TiO}_{2}$, hydrodeoxygenation, $\mathrm{HMF}, \mathrm{DMF}$ 


\section{Introduction}

Lignocellulosic biomass is one of the most abundant renewable source of commodity chemicals $[1,2]$ 5-(hydroxymethyl)furfural (HMF) that can be obtained via cellulose hydrolysis has been identified as valuable fuel, polymer, or chemical precursor.[3-5] Depending on the catalysts and reaction conditions HMF can be transformed towards a large variety of chemicals including 2,5-dimethylfuran (DMF), 5-methylfurfural (5-MF) or 2,5-bishydroxymethyltetrahydrofuran (BHMTHF) through hydrodeoxygenation (HDO) reaction (scheme 1).[6]

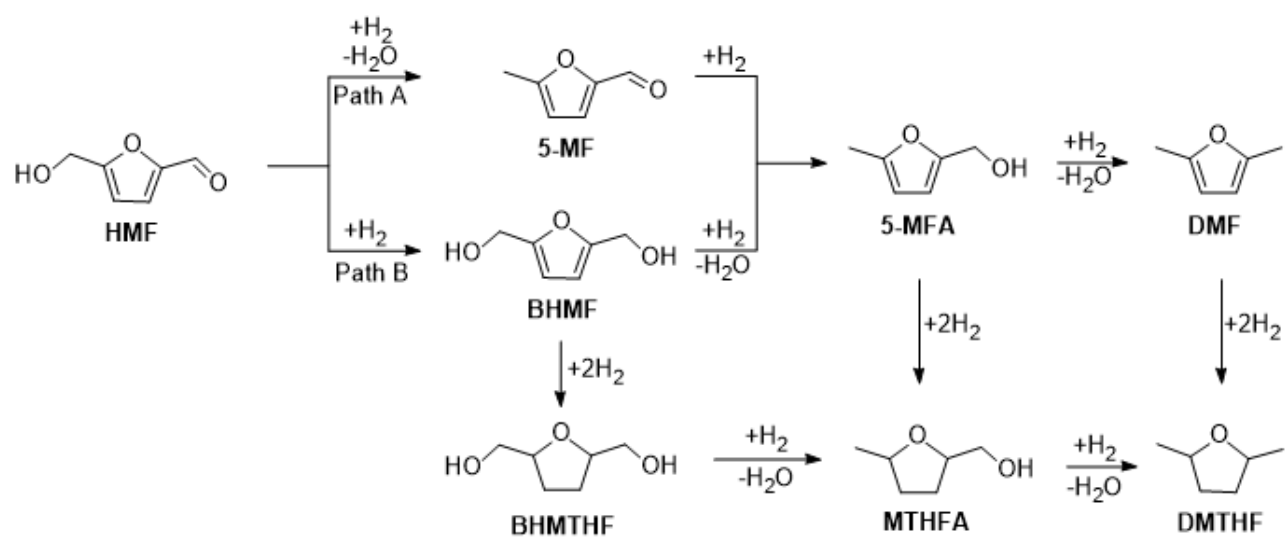

Scheme 1. Reaction pathway of HMF hydrodeoxygenation

Scheme 1 illustrates the HMF hydrodeoxygenation reaction pathway, with as first step the competitive HMF hydrodeoxygenation (path A) and hydrogenation (path B), that leads to the formation of 5-MF or of 2,5-bishydroxymethylfuran (BHMF). In the next step, BHMF undergoes a hydrodehydration reaction into 5-methylfurfuryl alcohol (5-MFA), while 5-MFA may also be obtained by hydrogenation of 5-MF. Next, 5-MFA undergoes either hydrogenation into 5-methyltetrahydrofurfuryl alcohol (MTHFA), or hydrodehydration with the formation of DMF which can be further hydrogenated to 2,5- dimethyltetrahydrofuran (DMTHF). DMTHF 
may also be obtained via the hydrodeoxygenation of BHMTHF, through the formation of the MTHFA intermediate. [7]

Among the HMF hydrodeoxygenation products, DMF and BHMTHF gained special attention due to their properties and functionalities. BHMTHF has been used as an green solvent, an intermediate for pharmaceuticals production or can be considered as an analogue of 1,3/1,4-cyklohexanedimethanol which is used for polyester production, or can also be converted to 1,6-hexanediol which is an important monomer for special applications. [8-12]. DMF is known as a biofuel additive, competitive to known alternatives and fully compatible to the currently used engines thanks to physicochemical properties similar to those of gasoline.[13]

The crucial issue is related with the selective transformation of HMF towards desired components in economically feasible way. This can be achieved by the application of a selective and active catalyst or through the modification of the reaction conditions. Most of the works which concentrate on DMF and BHMTHF production via HMF hydrodeoxygenation describes catalysts based on noble metals such as $\mathrm{Pd}, \mathrm{Pt}, \mathrm{Rh}$ and $\mathrm{Ru}$ dispersed on oxide and carbon supports [14-20] giving less attention to their non-noble counterparts. [21], [22] Noble metal catalysts exhibit high activity and selectivity; however they suffer from important drawbacks, such as the need to operate under strict reaction conditions, relatively high price, limited abundance and stability issue, that alternatively could be overcome by the application of robust non-noble metal based catalysts.[5],[23]

Kong et.al. and Lima et al. studied bulk Raney®-type metals for HMF to DMF hydrogenation. While Raney $\mathrm{Cu}$ showed poor performance in the model reaction, $\mathrm{Co}$ and $\mathrm{Ni}$ Raney based catalysts gave promising results, with the latter being superior. Eventually, a switchable synthesis of DMF and BHMTHF over Raney ${ }^{\circledR}$ Ni was developed with $96 \%$ and $88.5 \%$ yield respectively, depending on the reaction temperature $\left(100^{\circ} \mathrm{C}\right.$ for BHMTHF and 
$180^{\circ} \mathrm{C}$ for DMF).[24] However, long reaction time (up to $30 \mathrm{~h}$ ) and high Ni content (93\%) were required to reach this activity. By contrast, Lima et al. reported that highly selective HMF hydrogenation could be obtained in a two-stage process using consecutively Raney ${ }^{\circledR} \mathrm{Cu}$ and Ni catalysts [25].

Studies devoted to non-noble metals as active phase concerned mainly mono and bimetallic Ni-based catalysts supported on transition metal oxides such as $\mathrm{Al}_{2} \mathrm{O}_{3}, \mathrm{WO}_{3}$ or $\mathrm{TiO}_{2}$ [26-29]. One of the important factors that may affect the activity of the catalytic systems is the dispersion of the metal on the support surface. Siddiqui et al. showed that highly dispersed $\mathrm{Ni} / \mathrm{WO}_{3}$ has superior selectivity to DMF (95\%).[28] Similarly, in the work of Goyal et al. high Ni dispersion was recognized as the key factor responsible for the good catalyst performance giving very high selectivity to DMF. In the latter case, high dispersion of Ni was reached thanks to the use of a mesoporous nitrogen-rich carbon material possessing high surface area.[30] The importance of the support was also highlighted in the work of Zhu et.al. [31] Particularly well-tuned support acidity for the selective formation of DMF was shown on the example of $\mathrm{Ni}$ - zirconium phosphate system. It was demonstrated that high Lewis acidity of the catalyst originating from zirconium vacant orbitals may enhance the Ni performance towards hydrodeoxygenation while a too strong acidity leads to the formation of overhydrogenated byproducts (via $\mathrm{C}=\mathrm{C}$ bond reduction and C-C cleavage). Unfortunately, high reaction time (20 h) and elevated temperature $240^{\circ} \mathrm{C}$ were required for getting high DMF yield. In the recent work of Seemala et al., [29] titania was shown as preferable support for $\mathrm{Cu}-\mathrm{Ni}$ catalysts in the HMF hydrodeoxygenation. By allowing the preferential segregation of metals on the surface - namely Ni with close contact with the $\mathrm{TiO}_{2}$ interface and $\mathrm{Cu}$ segregating at the Ni particle surface, high activity was reached. This segregation and preferential interaction of metals was not occurring on other non-reducible supports such as $\mathrm{SiO}_{2}$ and $\mathrm{Al}_{2} \mathrm{O}_{3}$. [32][33] 
Nevertheless, limited demonstration of a successful application of titania as a part of catalytic system in HMF hydrogenation is reported. From the other hand, it is known that the properties of titania can significantly influence the supported metal nanoparticles, and that often the titania properties are the driving force for the catalysts' activity. In the example of the levulinic acid hydrogenation, Ru supported on anatase or rutile phase exhibited fully different mean particle sizes, strength of interaction with the support and in consequence activity in the reaction. [34] A similar phenomena was noticed for Ni-based catalysts in the hydrogenation of p-nitrophenol, for which the catalytic activity of the anatase titania supported nickel catalyst was much higher than that of its rutile titania supported counterparts. The authors explained this superiority in terms of difference in the reduction behavior, and facilitation of reduction in the anatase based support.[35] In contrast, rutile-based catalysts were more active in the hydrogenation of acetophenone over $\mathrm{Ni} / \mathrm{TiO}_{2}$ in comparison to their anatase counterparts.[36] This was attributed to the electronic interaction between $\mathrm{Ni}$ and rutile which promotes the formation of electron enriched nickel species at the rutile surface which interact with the carbonyl group of acetophenone and therefore enhance activity.

So, the catalytic activity of $\mathrm{Ni}$ is strongly depending on both the type and the properties of the support used. Well-tuning the acidity may enable either HDO or furan ring hydrogenation, while the development of strong metal-support interaction (SMSI) may enhance the metal dispersion and affect the particle size, consequently influencing the activity. Therefore, in our work we were for the first time investigating on the use of different types of titania materials varying in terms of polymorph nature and morphology -, as oxide supports in the catalytic hydrodeoxygenation of HMF in high pressure solvothermal reaction conditions. We compared anatase, rutile and bronze titania materials giving special attention to the one-dimensional (ie. high aspect ratio) supports prepared through the Kasuga-type hydrothermal synthesis method. This study allowed us to tune the activity of the supported catalysts to DMF or BHMTHF and 
to understand which properties of the titania support are the driving force for the reaction selectivity.

\section{Materials and methods}

Several $\mathrm{TiO}_{2}$ supports were used: anatase-rutile mixed phase Aeroxide $\left(\mathrm{TiO} \mathrm{Ti}_{2} \mathrm{P} 25\right.$ and $\mathrm{P} 90$ were delivered by Evonik-Degussa (Germany). Hombikat UV100 and Cristal ACTIV PC500 consisting of pure anatase $\mathrm{TiO}_{2}$ were delivered by Sachtleben Chemie GmbH (Germany) and Millenium-Crystal (France), respectively.

5-Hydroxymethylfurfural (98\%) was purchased from Fluorochem Ltd (United Kingdom), $\mathrm{Ni}\left(\mathrm{NO}_{3}\right)_{2} \cdot 6 \mathrm{H}_{2} \mathrm{O}(98 \%)$ was purchased from Chempur (Poland). 1,4-dioxane (99\%) was purchased from Merck (Germany).

\subsection{Hydrothermally prepared materials}

High aspect ratio nanofibers (NF) and nanoplates (NP) were obtained through a Kasuga-type synthesis consisting in applying a hydrothermal treatment in concentrated basic conditions to a titania solid used as titanium precursor. In a typical synthesis, $1.5 \mathrm{~g}$ of Aeroxide $\mathbb{C} \mathrm{TiO}_{2} \mathrm{P} 25$ powder were hydrothermally-treated in $90 \mathrm{~mL}$ of concentrated $10 \mathrm{M} \mathrm{NaOH}$ solution at a temperature of $150^{\circ} \mathrm{C}$ or $200^{\circ} \mathrm{C}$, respectively, for $24 \mathrm{~h}$ in a $150 \mathrm{~mL}$ teflon-lined stainless steel autoclave. The $\mathrm{TiO}_{2}$ suspension was previously maintained under stirring at $360 \mathrm{rpm}$ for $1 \mathrm{~h}$ for improving the particle dispersion. After the hydrothermal treatment, the white powder obtained was filtered, washed with $0.5 \mathrm{M} \mathrm{HCl}$ solution till acidic $\mathrm{pH}$ and further with demineralized water till neutral $\mathrm{pH}$ before being overnight dried at $100^{\circ} \mathrm{C}$. Then dried powder was further grinded and finally calcined at $500^{\circ} \mathrm{C}$ for $3 \mathrm{~h}$, with a heating rate of $2^{\circ} \mathrm{C} / \mathrm{min}$. 


\subsection{Catalyst preparation}

Catalysts with 5 wt.\% and 10 wt.\% of $\mathrm{Ni}$ content were prepared through the wet impregnation method of different types of $\mathrm{TiO}_{2}$ as supports using $\mathrm{Ni}\left(\mathrm{NO}_{3}\right)_{2} \cdot 6 \mathrm{H}_{2} \mathrm{O}$ as precursor salt and water as solvent. After the solvent evaporation, the catalysts were dried at $120^{\circ} \mathrm{C}$ for 2 $\mathrm{h}$ with subsequent calcination in the air flow at a temperature of $500^{\circ} \mathrm{C}$ for $5 \mathrm{~h}$. After oxidation, the catalysts were reduced in hydrogen flow at $500^{\circ} \mathrm{C}$ for $1 \mathrm{~h}$.

\subsection{Characterization methods}

Temperature-programmed reduction (TPR) was performed on AMI1 system from Altamira Instruments, USA, equipped with a thermal conductivity detector and was used for examining the reducibility of catalysts. Before the measurement catalysts were calcined at $300^{\circ} \mathrm{C}$ (with a $10^{\circ} \mathrm{C} / \mathrm{min}$ heating rate) for $30 \mathrm{~min}$ in a mixture of 2 vol. $\% \mathrm{O}_{2}$ and 98 vol.\% $\mathrm{Ar}$ at a space velocity $\mathrm{W} / \mathrm{F}=1.11 \times 10^{-5} \mathrm{~g} / \mathrm{h} \mathrm{cm}^{3}$. TPR profiles were recorded from $35^{\circ} \mathrm{C}$ up to $800^{\circ} \mathrm{C}$, with a heating rate of $7^{\circ} \mathrm{C} / \mathrm{min}$, using a mixture of 5 vol. $\% \mathrm{H}_{2}$ and 95 vol. $\%$ Ar at a similar space velocity.

Temperature-Programmed Desorption (TPD) of $\mathrm{NH}_{3}$ system was used to study the acidity of the catalysts. The TPD-NH 3 experiments were carried out in a quartz flow homemade micro-reactor. Before all experiments, the freshly reduced catalyst surface was purified under the flow of $\mathrm{He}$ at $500^{\circ} \mathrm{C}$ for $30 \mathrm{~min}$. After the sample was cooled down to $100^{\circ} \mathrm{C}$, the $\mathrm{NH}_{3}$ was adsorbed on the catalyst surface at $100^{\circ} \mathrm{C}$ for $15 \mathrm{~min}$. Before TPD- $\mathrm{NH}_{3}$ experiment, physically adsorbed $\mathrm{NH}_{3}$ has been removed from the catalyst surface by purifying the sample with the He carrier gas for $15 \mathrm{~min}$ and then cooled to room temperature. The temperature programmed desorption of $\mathrm{NH}_{3}$ were carried out from room temperature to $500^{\circ} \mathrm{C}$ using a linear temperature $\operatorname{ramp}\left(25^{\circ} \mathrm{C} / \mathrm{min}\right)$. 
Time-of-Flight Secondary Ion Mass Spectrometry (ToF-SIMS) measurements were performed using an ION-TOF GmbH instrument (TOF-SIMS IV) equipped with a $25 \mathrm{kV}$ pulsed $\mathrm{Bi}^{+}$primary ion gun in the static mode. The samples were fixed to the sample holder by double sided adhesive tape. The analyzed area of the sample surface was $500 \mu \mathrm{m}$ x $500 \mu \mathrm{m}$. During analysis, a pulsed low-energy electron flood gun was used for charge neutralization.

X-ray diffraction (XRD) measurements were collected using a PANalyticalX'Pert Pro MPD diffractometer. The X-ray source was a copper long fine focus X-ray diffraction tube operating at $40 \mathrm{kV}$ and $30 \mathrm{~mA}$. Data were collected in the $5-90^{\circ} 2 \theta$ range with $0.0167^{\circ}$ step. Crystalline phases were identified by references to ICDD PDF-2 (version 2004) database. All calculations were performed with X'Pert High Score Plus computer program.

Scanning electron microscopy (SEM) was performed in secondary electron mode on a JEOL JSM-6700 F FEG microscope.

Transmission electron microscopy (TEM) was performed using a Philips CM200 in standard mode observation, equipped with thermo-ionic $\mathrm{LaB}_{6}$ filament, operating at a $200 \mathrm{kV}$ acceleration voltage. The samples were firstly grinded and sonicated in ethanol solution, before a drop of the solution was deposited onto a copper grid covered by holey carbon membrane for observation.

The Fourier Transform InfraRed spectroscopy (FTIR) spectra of CO adsorbed on nickel catalysts were registered on Nicolett 6700 spectrometer equipped with an MCT detector and a diffuse reflection chamber. Prior to exposure to carbon monoxide, the samples were reduced at an appropriate temperature in $5 \% \mathrm{H}_{2}$ in $\mathrm{Ar}$ for $1 \mathrm{~h}$, then cooled to room temperature in an argon flow to remove adsorbed hydrogen and background spectra were collected. CO adsorption was carried out at 5 bar pressure of 5\% CO in Ar for $30 \mathrm{~min}$. Each spectrum was recorded with a resolution of $4 \mathrm{~cm}^{-1}$ performing 64 scans. 


\subsection{Catalytic tests}

The catalysts were tested in the 5-hydoxymethylfurfural (HMF) hydrogenation in high pressure solvothermal reaction conditions. The activity tests were performed in liquid phase using 1,4-dioxane as solvent within a stainless-steel autoclave (Premex, Switzerland) hydrogenation reactor operating under pressurized hydrogen, with a reaction volume of $60 \mathrm{ml}$. The reactions were carried out with $1 \mathrm{~g}$ of HMF, $0.15 \mathrm{~g}$ of catalyst and $30 \mathrm{~mL}$ of 1,4-dioxane. The reactor was pressurized with hydrogen to $30 \mathrm{bar}$ and heated up to $220^{\circ} \mathrm{C}$ with a heating ramp of $6.5^{\circ} \mathrm{Cmin}^{-1}$, and the reaction was further carried at $220^{\circ} \mathrm{C}$ for $0.25-5 \mathrm{~h}$. The reactor was further cooled down and the remaining pressure was released. The obtained reaction mixture was then centrifuged to separate the catalyst from the product-containing solution. The products were subsequently analyzed on an Agilent 7820A GC instrument equipped with a CP-Wax 52 CB capillary column and flame ionization detector.

HMF conversion and product yields were calculated as follows:

$$
\begin{gathered}
\text { Conversion }=\frac{n_{H M F_{i}}-n_{H M F_{r}}}{n_{H M F_{i}}} \cdot 100 \% \\
\text { Yield }=\frac{n_{\text {prod }}}{n_{H M F_{i}}} \cdot 100 \%
\end{gathered}
$$

$\mathrm{n}_{\mathrm{HMFi}}$ and $\mathrm{n}_{\mathrm{HMFr}}$ being the number of moles of HMF molecules before and after the reaction, respectively, and $\mathrm{n}_{\text {prod }}$ being the number of moles of a given product in the reaction mixture. 


\section{Results}

\subsection{Characterization of the hydrothermally synthesized titania materials}

The morphology of the high aspect ratio titania materials obtained through hydrothermal syntheses was studied by SEM and TEM in Fig. 1 and 2, respectively. The morphology obtained differed strongly from the conventional morphology of commercially available titania, shown for comparison in Fig. 1. The images evidenced the total selectivity of the alkaline hydrothermal synthesis towards the high aspect ratio nanomaterials, with no nanopowder being observed in both samples whatever the hydrothermal synthesis temperature. The material synthesized at $150^{\circ} \mathrm{C}$ is composed of entangled nanostructures with an overall one-dimensional morphology, and highly agglomerated into micron-size fibrous clusters. The agglomeration is reported to occur already during the drying step, probably through water removal. [37] The images evidenced the nanofiber (NF) nature of the nanostructures (also labelled as nanorods), with a mean diameter of ca. 10-20 nm and short lengths of ca. $100 \mathrm{~nm}$. Since the pioneering works of Kasuga et al. [38] describing the hydrothermal synthesis of one-dimensional $\mathrm{TiO}_{2}$ or titanate nanostructures through the bending and rolling of titanate nanosheets, [39][40] the exact formation mechanism and the phase nature of such nanostructures remains still under debate.[41-44]

By contrast, the material hydrothermally synthesized at $200^{\circ} \mathrm{C}$ displayed a nanoplate (NP) structure (also labelled as nanoribbons), with a mean width of ca. 100-150 nm and lengths from $1 \mu \mathrm{m}$ to several $\mu \mathrm{m}$. The synthesis of such nanoplates or nanoribbons at $200^{\circ} \mathrm{C}$ was reported by Beuvier et al. [45] So, the nanostructure morphology was highly influenced by the hydrothermal synthesis temperature. This was attributed to the stability domains of the different phases in terms of temperature and of $\mathrm{NaOH}$ concentration as reported in Morgan et al. during the threestep soft chemistry Kasuga method.[46] 

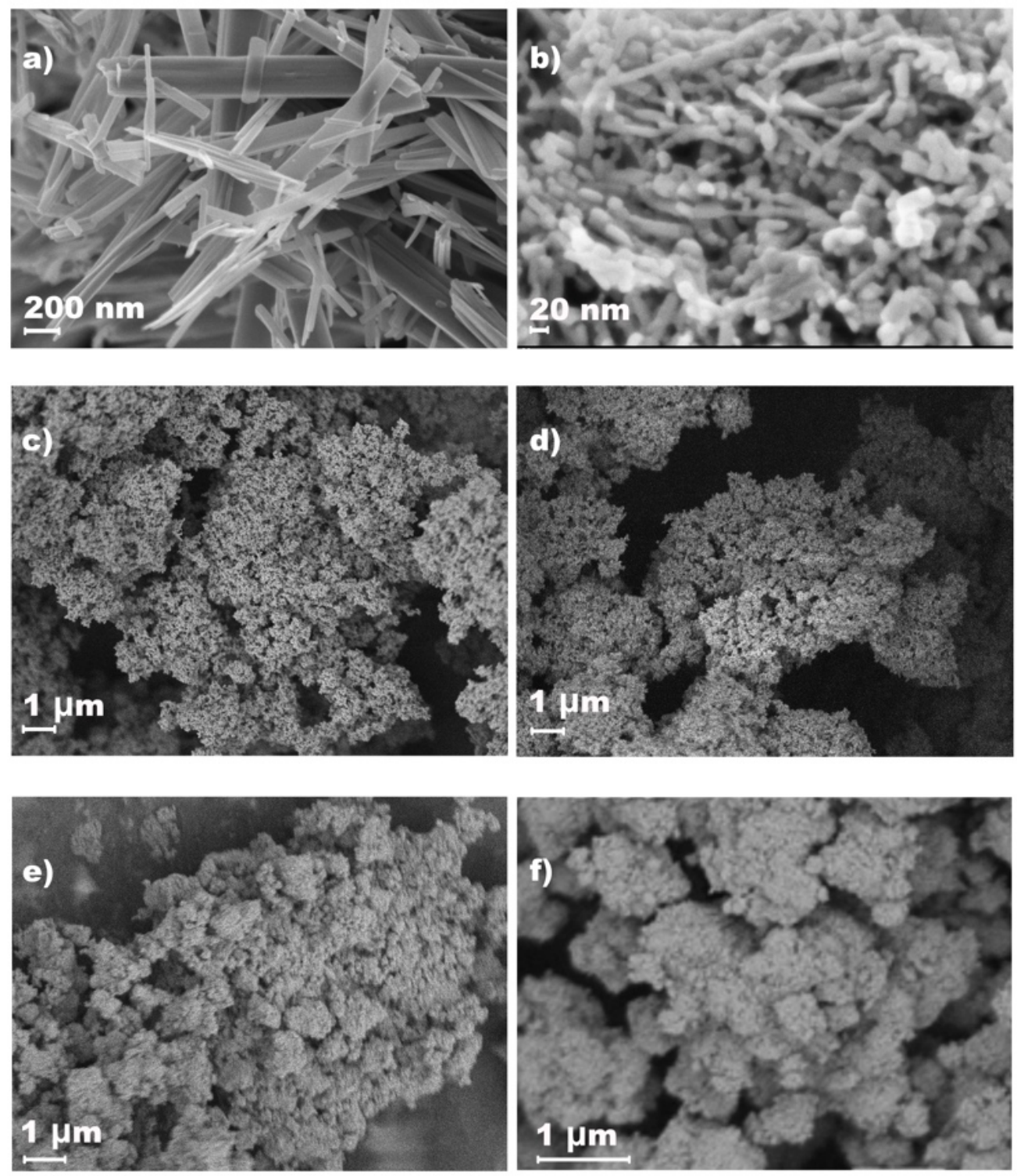

Figure 1 SEM images of a) NP and b) NF c) P25, d) P90, e) UV100 and f) PC500 titania materials 

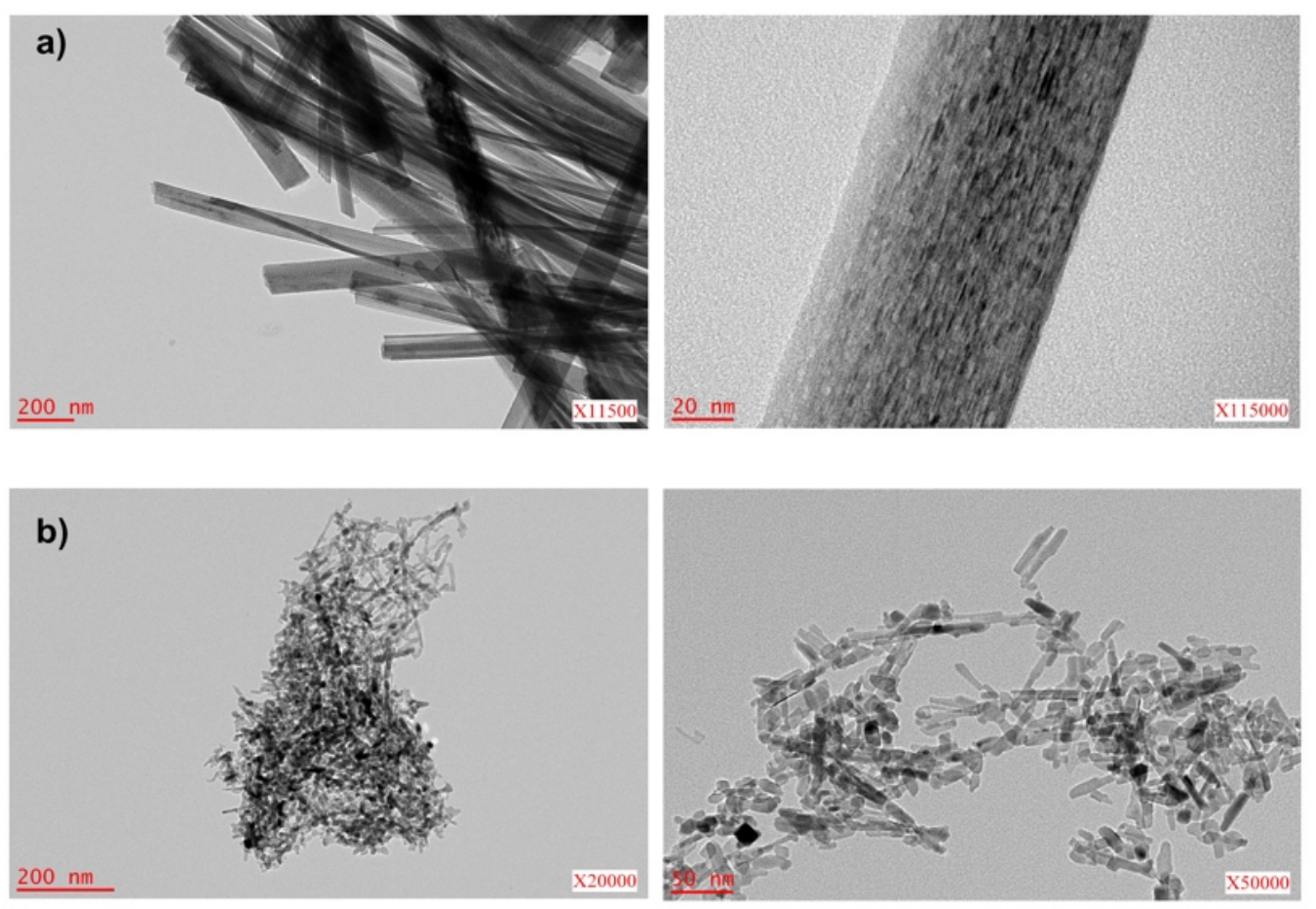

Figure 2 TEM images of a) NF and b) NP titania high aspect ratio materials prepared via hydrothermal synthesis. 


\subsection{Characterization of the $\mathrm{TiO}_{2}$ supported Ni catalysts}

\subsubsection{XRD analysis of the $10 \% \mathrm{Ni} / \mathrm{TiO}_{2}$ catalysts}

Figure 4 shows the XRD patterns of the catalysts and evidenced that the catalysts differ in terms of support phase compositions, taking into account the rutile (R) and anatase (A) or bronze (B) phase contribution. The main physico-chemical properties of the titania supports and of the $10 \% \mathrm{Ni} / \mathrm{TiO}_{2}$ catalysts are presented in Table 1 and 2 , respectively.

Both $\mathrm{TiO}_{2} \mathrm{P} 25$ and P90 supported Ni catalysts contain 20 and $10 \%$ of rutile, respectively, with the presence of the main rutile diffraction peaks at $2 \theta=27.5^{\circ}, 36.0^{\circ}$ and $41.2^{\circ}(\mathrm{JCPDS}$ 65-1119), in addition to the anatase as main crystalline phase, with the presence of the main anatase diffraction peaks at $2 \theta=25.3^{\circ}, 38.7^{\circ}, 48.0^{\circ}$ and $55.1^{\circ}(\mathrm{JCPDS} 65-5714)$. Other catalysts prepared on commercially available titania only contained anatase as support phase, whereas the nanoplate titania (NP) sample consists in a bronze (B) phase, with the most intense diffraction peaks at $2 \theta=24.9^{\circ}, 28.6^{\circ}, 29.7^{\circ}, 43.5^{\circ}, 44.5^{\circ}, 48.5^{\circ}, 57.6^{\circ}$ and $67.2^{\circ}(\operatorname{JCPDS} 00-$ 0461237).[47-49]

Similarly to the difference in morphology, the nature of the high aspect ratio nanostructures was also influenced by the hydrothermal synthesis temperature, as a result of the stability domains of the different phases studied by Morgan et al.[46] and Beuvier et al. [45], the NP materials crystallizing as bronze $\mathrm{TiO}_{2}(\mathrm{~B})$ at $500^{\circ} \mathrm{C}$, while the nanofibers crystallized as anatase.

The materials differ as well in terms of specific surface area, the rutile-based supports exhibiting medium BET surface area $\left(55-90 \mathrm{~m}^{2} / \mathrm{g}\right)$ which correlates with the presence of large mean size crystallites. By contrast, anatase-based titania exhibited much higher surface areas up to $336 \mathrm{~m}^{2} / \mathrm{g}$ in the case of the PC500 samples with smaller titania crystallites of $7 \mathrm{~nm}$ accordingly. The hydrothermally prepared high aspect ratio titania materials possess a nonmicroporous high specific surface area of $115 \mathrm{~m}^{2} / \mathrm{g}$ in the case of the short-length and small 
diameter nanofibers exposing a high external surface area. By contrast, the hydrothermally prepared nanoplates have a lower surface area of $18 \mathrm{~m}^{2} / \mathrm{g}$.

In all cases, diffraction reflexes assigned to metallic nickel at $2 \theta=44.5^{\circ}$ and $51.8^{\circ}$ (JCPDS 04-0850) were observed. The smallest mean size of nickel crystallites were observed for the catalysts supported on UV100 and PC500 titania, at $8 \mathrm{~nm}$, while the largest mean size of crystallites was obtained for rutile-containing materials (at $15 \mathrm{~nm}$ and $12 \mathrm{~nm}$ for P90 and P25, respectively) and for the NF support (13 nm).

Table 1 The main physico-chemical properties of titania materials

\begin{tabular}{|c|c|c|c|c|c|c|}
\hline & \multicolumn{5}{|c|}{$\mathrm{TiO}_{2}$ supports } & \multirow[b]{2}{*}{ NP. } \\
\hline & $\mathbf{P 2 5}$ & P90 & UV100 & PC 500 & $\mathbf{N F}$ & \\
\hline Composition of the & $\mathrm{R}: 21$ & $\mathrm{R}: 10$ & \multirow[b]{2}{*}{$\mathrm{A}$} & \multirow[b]{2}{*}{$\mathrm{A}$} & \multirow[b]{2}{*}{$\mathrm{A}$} & \multirow[b]{2}{*}{$\mathrm{B}$} \\
\hline crystallized phase [\%] & A: 79 & A: 90 & & & & \\
\hline Average crystallite size & $\mathrm{R}: 32$ & $\mathrm{R}: 23$ & \multirow[b]{2}{*}{9} & \multirow[b]{2}{*}{7} & \multirow[b]{2}{*}{-} & \multirow[b]{2}{*}{-} \\
\hline$[\mathbf{n m}]^{\mathrm{a}}$ & A: 22 & A: 13 & & & & \\
\hline BET surface area $\left[\mathrm{m}^{2} / \mathrm{g}\right]$ & 55 & 90 & 330 & 336 & 115 & 18 \\
\hline Pore volume $\left[\mathrm{cm}^{3} / \mathrm{g}\right]$ & 0.12 & 0.24 & 0.22 & 0.21 & - & - \\
\hline $\begin{array}{l}\text { a Determined from the XRD ana } \\
\text { anatase and rutile, at } 25.7^{\circ} \text { and } 2\end{array}$ & $\begin{array}{l}\text { by appl } \\
\text {, respecti }\end{array}$ & $\begin{array}{l}g \text { the Scl } \\
\text { ly, with t }\end{array}$ & $\begin{array}{l}\text { rrer equatic } \\
\text { classical }\end{array}$ & $\begin{array}{l}\text { to the }(10 \\
\text { sumption o }\end{array}$ & $\begin{array}{l}\text { and }(1 \\
\text { spheric }\end{array}$ & $\begin{array}{l}\text { eaks of } \\
\text { stallites }\end{array}$ \\
\hline
\end{tabular}


Table 2 Main physico-chemical properties of the $10 \% \mathrm{Ni} / \mathrm{TiO}_{2}$ catalysts

\begin{tabular}{cccccccc}
\hline Catalyst & Ni/P25 & Ni/P90 & Ni/UV100 & Ni/PC500 & Ni/NF & Ni/NP \\
\hline Size of crystallites $[\mathbf{n m}]^{\text {a }}$ & 12 & 15 & 8 & 8 & 13 & b \\
Acidity $\left[\boldsymbol{\mu m o l} / \mathbf{m}^{2}\right]^{\text {c }}$ & 1.7 & 2.8 & 0.5 & 0.4 & 0.3 & - \\
a Determined from the XRD analysis by applying the Scherrer equation to the mean diffraction of the metallic \\
nickel at $44.5^{\circ}$, with the classical assumption of spherical crystallites. \\
b Not measurable due to the overlapping with one diffraction peak of the $\mathrm{TiO}_{2}(\mathrm{~B})$ phase \\
c Determined through $\mathrm{NH}_{3}-\mathrm{TPD}$ analysis
\end{tabular}

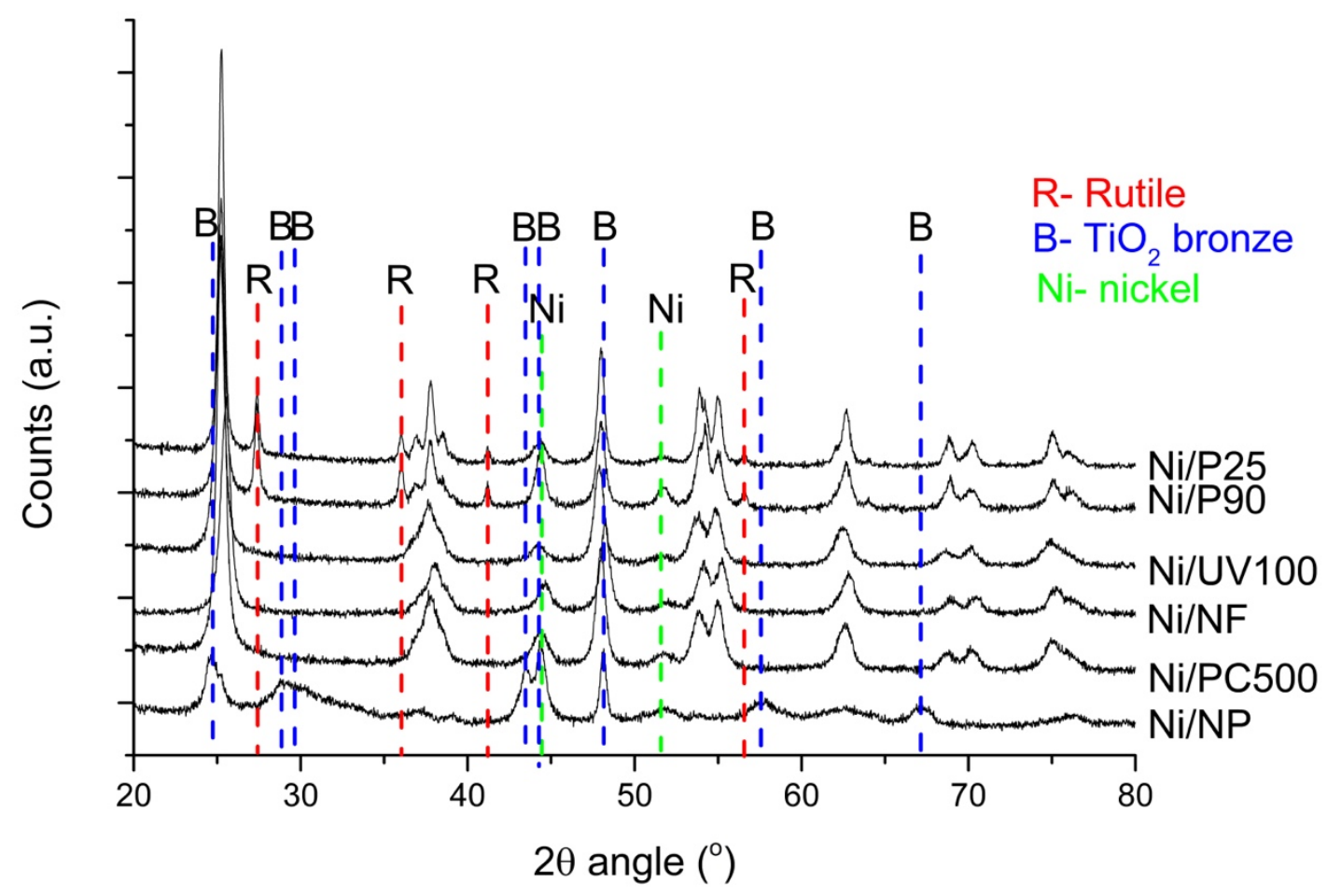

Figure 3 X-ray diffractograms of the $10 \% \mathrm{Ni} / \mathrm{TiO}_{2}$ catalysts. The non-assigned reflexes belong to the anatase structure 


\subsubsection{Temperature programmed reduction measurements}

The reducibility of the $\mathrm{Ni} / \mathrm{TiO}_{2}$ catalysts was studied by TPR measurements (Figure 4). Although the analysis was conducted in a broad range of temperatures $\left(30-800^{\circ} \mathrm{C}\right)$, the main reduction effect was observed in the $250-550^{\circ} \mathrm{C}$ range, so that only this temperature range is presented for highlighting the changes in between samples. The reduction profiles are characterized by the presence of one single reduction peak for all investigated catalysts, that however differs in terms of temperature range and maximum.

For $\mathrm{Ni}$ catalysts containing the rutile titania phase, both the maximum of hydrogen consumption (at $465^{\circ} \mathrm{C}$ and $460^{\circ} \mathrm{C}$ for $10 \% \mathrm{Ni} / \mathrm{P} 90$ and $10 \% \mathrm{Ni} / \mathrm{P} 25$, respectively) and the peak tail are located at high temperature. This can be assigned to $\mathrm{NiO}_{\mathrm{x}}$ strongly interacting with titania [50-52] or to the presence of large crystallites.[36]

For the anatase supported catalysts $(10 \% \mathrm{Ni} / \mathrm{UV} 100$ and $10 \% \mathrm{Ni} / \mathrm{PC} 500)$, the maximum of hydrogen consumption peak was shifted towards lower temperature (at $425^{\circ} \mathrm{C}$ and $420^{\circ} \mathrm{C}$, respectively). This may suggest the existence of weaker interactions between the $\mathrm{NiO}_{\mathrm{x}}$ phase and the titania support, in agreement with the literature.[53]

The TPR profile of supported on titania nanofibers and nanoplates are similar to each other. The reduction profile starts for them in lowest temperature among all investigated samples (around $300^{\circ} \mathrm{C}$ ). TPR profile is very broad and continues to high temperatures- almost like for rutile containing ones. This can be related with the presence of similar particle size and therefore similar $\mathrm{Ni}_{-} \mathrm{TiO}_{2}$ interaction like for rutile -based samples. Additionally, the presence of low temperature effects can be related with the presence of amorphous $\mathrm{NiOx}$ or $\mathrm{NiO}$ weakly interacting with the support. In the case of $\mathrm{Ni} / \mathrm{NP}$, this low temperature effect is more pronounced so that a low temperature maximum can be evidenced. This might result from the titania bronze nature of the support. 


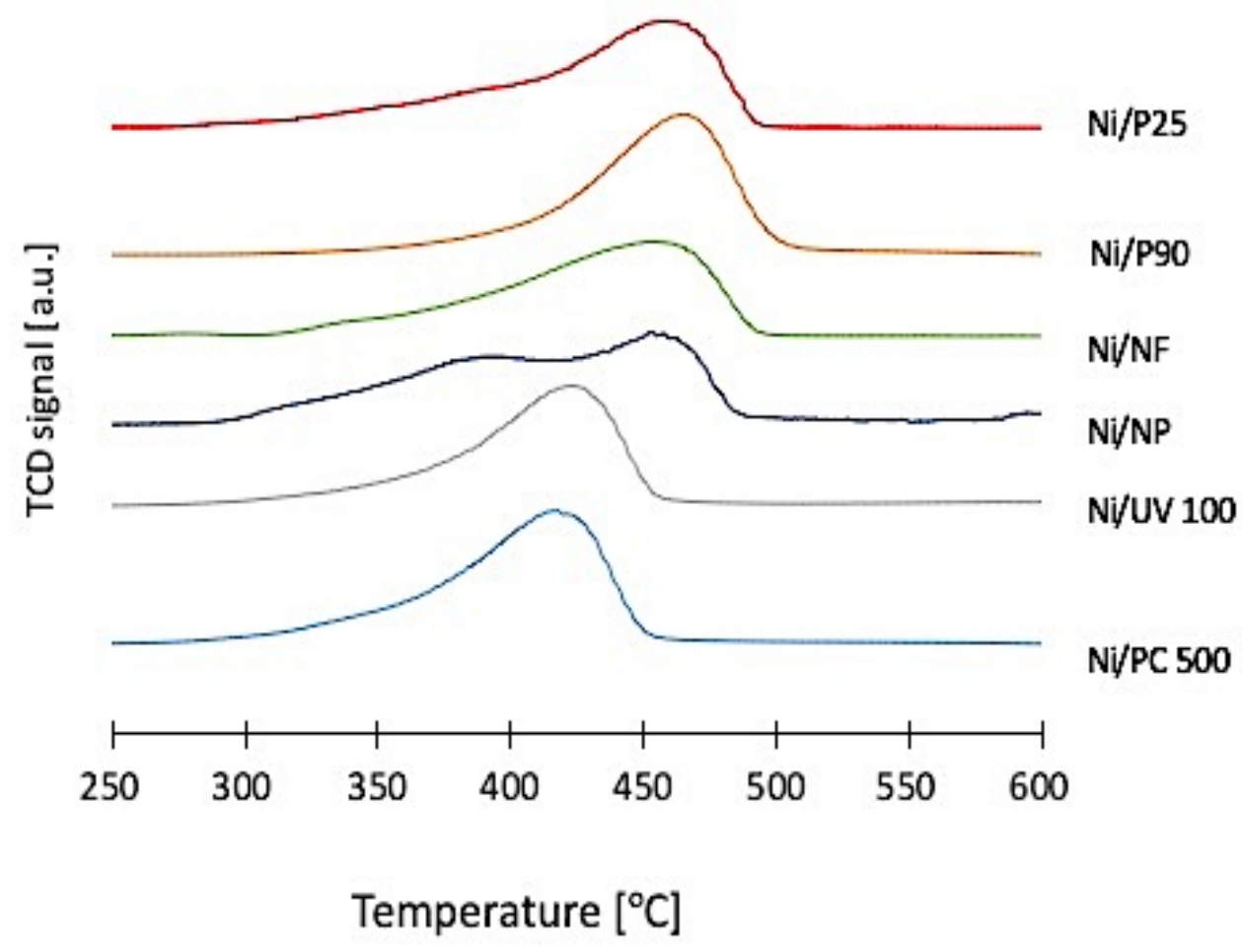

Figure 4 Temperature programmed reduction profiles of the $10 \% \mathrm{Ni} / \mathrm{TiO}_{2}$ catalysts

\subsubsection{Acidity}

The acidity of the catalysts was investigated by $\mathrm{NH}_{3}$-TPD analysis. The highest concentration of acid sites was observed for the rutile-containing catalysts, particularly for Ni/P90. In contrast, the anatase-based materials showed significantly lower values $\left(0.4-0.5 \mu \mathrm{mol} / \mathrm{m}^{2}\right)$ and the lowest one for the hydrothermally prepared material $\left(0.3 \mu \mathrm{mol} / \mathrm{m}^{2}\right)$. It is well known that on the surface of titanium oxide is only composed of Lewis acid centers and that Brönsted acidity on the titania surface is the result of its interaction with water.[54] Scaranto et al. showed that the Lewis acidity of anatase and rutile is comparable, whereas acid centers on the surface of rutile are more electrophilic.[55] Taking this into account, the higher acidity of the rutilecontaining catalysts compared to the anatase based samples is associated with the availability 
of the surface Lewis acid centers and the polymorphic nature of $\mathrm{TiO}_{2}$ has no major effect on the concentration of acid centers.

\subsubsection{Time-of-flight secondary ion mass spectrometry analysis}

Selected ions intensity identified on the surface of the catalysts by ToF-SIMS analysis are presented in Table 3. The relative nickel ions intensity on the catalyst surface, shown here as $\mathrm{Ni}^{+} / \mathrm{Ti}^{+}$ratio, differ for the different analyzed samples. The highest ratio of $\mathrm{Ni}^{+} / \mathrm{Ti}^{+}$ions was identified for the anatase-based materials, giving similar high values (5.7 and 4.0 for Ni/PC500 and Ni/UV100, respectively). This suggests that Ni crystallites are well-dispersed on the surface of these catalysts.[56] In contrast, the rutile-containing catalysts (Ni/P90 and Ni/P25) exhibited the lowest ratio of $\mathrm{Ni}^{+} / \mathrm{Ti}^{+}$ions, probably due to the presence of large $\mathrm{Ni}$ crystallites, in agreement with the XRD results. The catalysts based on the hydrothermally prepared supports (Ni/NF and $\mathrm{Ni} / \mathrm{NP})$ showed similar $\mathrm{Ni}^{+} / \mathrm{Ti}^{+}$ratio, at 3.0 and 3.4 respectively.

Table 3 Normalized intensity of selected ions calculated on the basis of ToF-SIMS spectra collected from the surface of the $10 \% \mathrm{Ni} / \mathrm{TiO}_{2}$ catalysts

\begin{tabular}{lccc}
\hline Catalyst & \multicolumn{3}{c}{ Normalized intensity of selected ions identified on the catalysts surface } \\
\hline & $\mathrm{Ni}^{+} / \mathrm{Ti}^{+}\left(\mathrm{x} 10^{-1}\right)$ & $\mathrm{Ti}^{+} /$total $\left({\left.\mathrm{x} 10^{-1}\right)}^{-1}\right.$ & $\mathrm{NiTiO}^{+} / \mathrm{Ni}^{+} \cdot\left(\mathrm{x}^{-3}\right)$ \\
\hline $\mathbf{N i} / \mathbf{P C 5 0 0}$ & 5.7 & 0.6 & 5.0 \\
$\mathbf{N i} / \mathbf{U V 1 0 0}$ & 4.0 & 0.8 & 5.6 \\
$\mathbf{N i} / \mathbf{P 9 0}$ & 1.9 & 1.2 & 7.2 \\
$\mathbf{N i} / \mathbf{P 2 5}$ & 2.1 & 1.3 & 5.8 \\
$\mathbf{N i} / \mathbf{N F}$ & 3.0 & 1.1 & 6.7 \\
$\mathbf{N i} / \mathbf{N P}$. & 3.4 & 1.1 & - \\
\hline
\end{tabular}


Furthermore, the presence of $\mathrm{NiTiO}^{+}$ion was observed on the surface, which may suggest the existence of a strong interaction between nickel and titania or the presence of interfacial phase such as e.g. nickel titanate. The presence of this ion was detected for all samples, except in the case of $\mathrm{Ni} / \mathrm{NP}$. The highest ratio $\mathrm{NiTiO} / \mathrm{Ni}^{+}$was detected for rutile-based samples particularly $\mathrm{Ni} / \mathrm{P} 90$. For anatase-containing materials, the highest $\mathrm{NiTiO}^{+} / \mathrm{Ni}^{+}$ions intensity was observed in the case of $\mathrm{Ni} / \mathrm{NF}$, while the lowest values were detected for the high-surface area anatase samples. This may indicate the establishment of stronger interactions of the rutile phase with $\mathrm{NiO}_{x}$ crystallites, in agreement with the literature. [53]

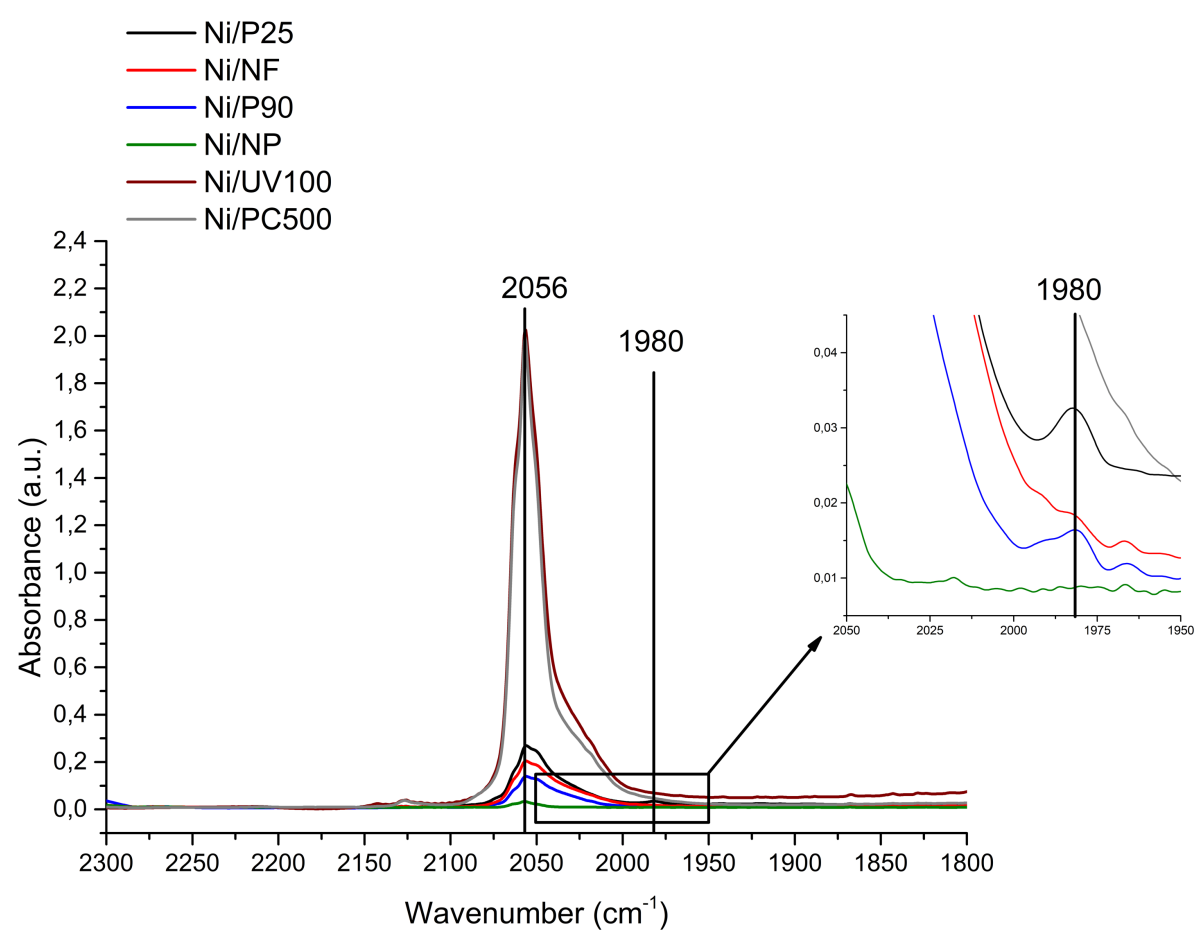

Figure $5 \mathrm{CO}$-adsorbed FTIR spectra of $10 \% \mathrm{Ni} / \mathrm{TiO}_{2}$ catalysts

\subsubsection{FTIR analysis}

Generally, the bands in the FTIR-CO spectra of nickel based catalysts in the $2100-2000 \mathrm{~cm}^{-}$

${ }^{1}$ range are attributed to the linear adsorption of $\mathrm{CO}$ on metallic nickel crystallites, while the bands below $2000 \mathrm{~cm}^{-1}$ are assigned to bridged $\mathrm{CO}$ adsorption on the metal crystallites. [57-60] 
Therefore, the band observed at $2056 \mathrm{~cm}^{-1}$ in the spectra of the $\mathrm{Ni} / \mathrm{TiO}_{2}$ catalysts is assigned to physically adsorbed nickel carbonyl and the band at $2020 \pm 5 \mathrm{~cm}^{-1}$ appearing as a shoulder characterizes the linear CO adsorption on isolated nickel crystallites.[61-64] The highest intensity of both bands in the spectra of the pure anatase catalysts (Ni/PC500 and Ni/UV100) is due to the presence of small nickel crystallites with a high dispersion. Analogously, the lower intensity of the bands at $2056 \mathrm{~cm}^{-1}$ and $2020 \pm 5 \mathrm{~cm}^{-1}$ results from higher aggregation and lower dispersion of the nickel on the surface of hydrothermal titania and rutile-containing catalysts. Lower nickel dispersion explains the appearance of the band at $1980 \mathrm{~cm}^{-1}$ attributed to bridged CO adsorption. 
Table 4 Catalytic activity of the $\mathrm{Ni} / \mathrm{TiO}_{2}$ catalysts in $\mathrm{HMF}$ hydrodeoxygenation

\begin{tabular}{|c|c|c|c|c|c|c|c|c|c|c|}
\hline \multirow[t]{2}{*}{ Catalyst } & \multirow{2}{*}{$\begin{array}{c}\text { Reaction } \\
\text { time }[h]\end{array}$} & \multicolumn{3}{|c|}{ Conversion [\%] } & \multicolumn{3}{|c|}{ Product yield [\%] } & \multirow{2}{*}{$\begin{array}{l}\text { MTHFA } \\
Y^{0} \Upsilon_{\mathrm{OH}}\end{array}$} & \multirow{2}{*}{$\begin{array}{c}\text { DMTHF } \\
Y^{0} Y\end{array}$} & \multirow[b]{2}{*}{ Others } \\
\hline & & HMF & 5-MF & BHMF & BHMTHF & 5-MFA & DMF & & & \\
\hline $\mathrm{Ni} / \mathrm{P} 25$ & 0.25 & 93 & 8 & 4 & 3 & 17 & 45 & 1 & 0 & 15 \\
\hline $\mathrm{Ni} / \mathrm{P} 25$ & 0.5 & 98 & 5 & 3 & 4 & 16 & 57 & 2 & 1 & 10 \\
\hline $\mathrm{Ni} / \mathrm{P} 25$ & 1 & 100 & 0 & 0 & 6 & 0 & 69 & 3 & 22 & 0 \\
\hline $\mathrm{Ni} / \mathrm{P} 25$ & 2 & 100 & 0 & 0 & 6 & 1 & 24 & 6 & 54 & 9 \\
\hline $\mathrm{Ni} / \mathrm{PC} 500$ & 0.25 & 89 & 23 & 0 & 0 & 14 & 44 & 0 & 0 & 8 \\
\hline $\mathrm{Ni} / \mathrm{PC500}$ & 0.5 & 98 & 17 & 0 & 0 & 4 & 69 & 1 & 1 & 6 \\
\hline $\mathrm{Ni} / \mathrm{PC} 500$ & 1 & 98 & 20 & 0 & 0 & 3 & 71 & 1 & 1 & 2 \\
\hline $\mathrm{Ni} / \mathrm{PC500}$ & 2 & 100 & 2 & 0 & 0 & 1 & 85 & 0 & 5 & 7 \\
\hline $\mathrm{Ni} / \mathrm{P9O}$ & 1 & 100 & 0 & 0 & 18 & 0 & 54 & 2 & 26 & 0 \\
\hline Ni/P90 & 2 & 100 & 0 & 0 & 8 & 0 & 54 & 5 & 29 & 4 \\
\hline $\mathrm{Ni} / \mathrm{UV} 100$ & 1 & 99 & 29 & 1 & 1 & 18 & 49 & 0 & 0 & 1 \\
\hline $\mathrm{Ni} / \mathrm{UV} 100$ & 2 & 100 & 6 & 0 & 0 & 4 & 79 & 2 & 6 & 3 \\
\hline $\mathrm{Ni} / \mathrm{NP}$ & 1 & 100 & 5 & 30 & 58 & 6 & 0 & 0 & 1 & 0 \\
\hline $\mathrm{Ni} / \mathrm{NF}$ & 1 & 100 & 0 & 0 & 58 & 1 & 19 & 6 & 5 & 11 \\
\hline $\mathrm{Ni} / \mathrm{P} 25^{(1)}$ & 1 & 100 & 1 & 0 & 17 & 0 & 54 & 0 & 28 & 0 \\
\hline
\end{tabular}

Reaction conditions: $220^{\circ} \mathrm{C}$; time $0.25-2 \mathrm{~h} ; 0.15 \mathrm{~g}$ of catalyst; $1 \mathrm{~g}$ of HMF; $30 \mathrm{ml}$ of dioxane; 30 bar of hydrogen.

(1) the catalyst was prepared by calcination at $400^{\circ} \mathrm{C}$ and subsequent reduction at $350^{\circ} \mathrm{C}$. Used as reference allowing to compare with the hydrothermally-prepared materials which required lower temperature treatment 


\subsubsection{Catalytic activity}

The activity of the $\mathrm{Ni} / \mathrm{TiO}_{2}$ catalysts in $\mathrm{HMF}$ hydrodeoxygenation was presented in the Table 4. By comparing the results obtained with the catalysts supported on different $\mathrm{TiO}_{2}$ materials, very clear tendencies can be noticed. Looking to the evolution of the reaction performance with time for the catalyst supported on $\mathrm{P} 25$ (ie. rutile-containing $\mathrm{TiO}_{2}$ ), it is clearly possible to observe that although the DMF was the main reaction product $(0.25-1 \mathrm{~h})$, the reaction was proceeding further, and the reduction of the furan ring occurred with a significant DMTHF yield (54\%) for a longer reaction time. This in consequence did not allow to reach high yield of DMF. Similar tendency was noticed in the case of another rutile-containing catalyst Ni/P90, where the highest yield to DMF was only $54 \%$, as a significant amount of DMTHF was already present after $1 \mathrm{~h}$. DMTHF yield did not increase significantly for longer reaction time, which could be related to the catalyst deactivation or due to the fact that this reaction step is a slow step due to a large energetic barrier.[13] In the case of the rutile-containing materials, we observed also a significant amount of BHMTHF. This suggests that path B (via BHMF) cannot be excluded as typically observed for Ni/C [13]. Lack of significant amount of BHMF can be related with the fact that the formation of BHMF is slow and is usually a rate limiting step [13] [65] in comparison to the fast formation of 5-MFA.

In contrast, a different behavior was observed in the case of the anatase $\mathrm{TiO}_{2}$ supported catalyst Ni/PC500. Here high yield to DMF was kept already in the early reaction time $(0.5 \mathrm{~h}-$ $69 \%$ ) and was continuously increasing for reaching $85 \%$ after $2 \mathrm{~h}$. The same observation can be noted for the other anatase-based material Ni/UV100 - DMF yield is continuously increasing and no further hydrogenation products are observed. In the latter case, significant yields to 5MF and 5-MFA were observed and only traces of BHMF were detected. This might suggest 
that the reaction proceeds preferentially in that case via hydrogenolysis towards 5-MF, followed by $\mathrm{C}=\mathrm{O}$ hydrogenation to 5-MFA and final hydrogenolysis to DMF (path A). Such a path was also identified for $\mathrm{Ni} /$ zirconia based materials and explained by the presence of Lewis acid sites, which facilitated the first step of the reaction.[31]"

The presence of significant amount of BHMF was observed mainly in the case of $10 \% \mathrm{Ni} / \mathrm{NP}$ catalyst. Interestingly, for both hydrothermally-prepared materials, the main reaction product was BHMTHF, that is a further ring-hydrogenation product issued from BHMF, and in both cases with a very high yield (58\%) was noted. This suggests that the hydrogenation step was favored in both cases, whereas the hydrogenolysis of C-O was occurring only marginally, giving a maximum yield of only $19 \%$ towards the DMF by-product in the case of $10 \% \mathrm{Ni} / \mathrm{NF}$.

Additional results obtained for a lower Ni loading of 5\% and for other reaction times are reported in Table S1 for selected catalysts.

\section{Discussion}

The significant support effect observed with $\mathrm{Ni} / \mathrm{TiO}_{2}$ catalysts in the $\mathrm{HMF}$ hydrodeoxygenation can be rationalized through the catalyst characterization studies. Based on the results, it is clear that the titania properties determine the size of the supported Ni particles, the character of the metal-support interaction and the catalyst acidity, with consequently a strong influence on the catalytic activity.

Large specific surface area anatase materials facilitate the formation of small Ni particles with a high dispersion. As a result, the surface exposed by the titania is reduced, so that the catalysts exhibit a moderate acidity. In contrast, the presence of the rutile phase induces the 
existence of stronger Ni-support interactions. Rutile - as the more thermally stable phase usually possesses a smaller specific surface area and in consequence larger Ni particles are formed. Additionally, for those materials, a significant acidity is observed.

Those features play a key role in hydrogen adsorption, as it is known that there is a significant electronic interaction between $\mathrm{Ni}$ and rutile, which can enhance the hydrogen adsorption,[36] in contrast to the Ni/anatase counterparts. From the other hand, H atoms may act as a 'poison' for the Ni surface due to its strong adsorption on the metal surface.[66] This effect is stronger in the case of smaller Ni crystallites which can even act as 'hydrogen storage' phase, whereas the adsorption/desorption of hydrogen is facilitated on larger Ni crystallites.[67] Therefore this suggests that the hydrogenation reaction might proceed via both 5-MF and BHMF paths in the case of the rutile-containing materials such as P90 and P25, for which large Ni crystallites are present. Further, the preferred adsorption in that case occurs most probably via $\eta^{2}(\mathrm{C}=\mathrm{O})$ which brings aromatic ring close to the surface, consequently allowing its reduction and therefore allowing only in this case the production of DMTHF in significant amount through the reduction of the furanic ring.[29]

The hydrothermally-prepared Ni/NF material stabilized relatively large Ni particles, and therefore favored the reaction path via BHMF. However, due to the low acidity of the catalyst further reactions of $\mathrm{C}-\mathrm{O}$ hydrogenolysis were strongly limited and therefore BHMTHF was formed as the main reaction product due to further reduction of BHMF on Ni particles. Although the mean size of the Ni particles could not be determined on the Ni/NP material, both high aspect ratio catalysts displayed similar $\mathrm{Ni}^{+} / \mathrm{Ti}^{+}$and $\mathrm{Ti}^{+} /$total ratios in $\mathrm{ToF}-\mathrm{SIMS}$, so that a similar mean Ni particle size might be hypothesized in both cases, explaining that the BHMF reaction path was preferred on both catalysts.

The situation is different in the case of the large surface area anatase Ni/PC500 and Ni/UV100 catalysts. Here, the presence of acid sites and small metal particles which strongly 
adsorb hydrogen and limit its desorption, favors possibly the path via hydrogenation and dehydration with the formation of 5-MF. In that case, on small Ni particles the ring-surface interaction is also limited, so that only traces of DMTHF were consequently observed.

A similar important role played by the metallic particle size was reported by the Somorjai's group in the vapor phase furfural hydrogenation. [68] The authors observed that the reaction path - and consequently the product selectivity - was highly dependent on the nanoparticle size in the case of $\mathrm{Pt} / \mathrm{SiO}_{2}$ catalysts, small particles being found to form predominantly furan via decarbonylation, whereas larger sized particles yielded both furan and furfuryl alcohol, the carbonyl hydrogenation product.

\section{Conclusions}

The activity of $\mathrm{TiO}_{2}$ supported $\mathrm{Ni}$ catalysts varying in terms of morphology and crystallographic structure of the support has been investigated in the HDO of HMF. It is clear that the titania properties determine strongly the character of the supported nickel nanoparticles (in terms of both the size and the strength of the interaction with the support). By tuning the titania properties, we can force the selectivity towards the desired product.

Rutile-containing titania stabilizing larger Ni crystallites forced the existence of stronger NiTi interactions and enhanced hydrogen adsorption, which resulted in high activity. Although DMF is the main reaction product, the reaction is pushed forward towards the production of DMTHF through the reduction of the furanic ring in that case.

Hydrothermally-prepared materials allowed to obtain selectively 2,5-bishydroxymethyltetrahydrofuran due a relatively low surface acidity and large Ni particles. By contrast, the large surface area anatase with small nickel particles allowed to achieve high selectivity to DMF $(85 \%)$. 


\section{Acknowledgements}

The authors gratefully acknowledge that this work was financially supported by a grant SONATA BIS from the National Center of Science (NCN) in Krakow (Poland) (2016/22/E/ST4/00550).

\section{References}

[1] A. Shrotri, H. Kobayashi, A. Fukuoka, Cellulose Depolymerization over Heterogeneous Catalysts, Acc. Chem. Res. 51 (2018) 761-768. doi:10.1021/acs.accounts.7b00614.

[2] E. Soszka, H. M. Reijneveld, M. Jędrzejczyk, I. Rzeźnicka, J. Grams, A. M. Ruppert, Chlorine Influence on Palladium Doped Nickel Catalysts in Levulinic Acid Hydrogenation with Formic Acid as Hydrogen Source, ACS Sustainable Chem. Eng. 6(11) (2018) 14607-14613.

[3] S. Chen, R. Wojcieszak, F. Dumeignil, E. Marceau, S. Royer, How Catalysts and Experimental Conditions Determine the Selective Hydroconversion of Furfural and 5-Hydroxymethylfurfural, Chem. Rev. 118 (2018) 11023-11117. doi:10.1021/acs.chemrev.8b00134.

[4] M. Sasaki, B. Kabyemela, R. Malaluan, S. Hirose, N. Takeda, T. Adschiri, K. Arai, Cellulose hydrolysis in subcritical and supercritical water, J. Supercrit. Fluids. 13 (1998) 261-268. doi:10.1016/S0896-8446(98)00060-6.

[5] D.A. Cantero, A. Alvarez, D. Bermejo, J. Cocero, Transformation of glucose into added value compounds in a hydrothermal reaction media, J. Supercrit. Fluids. 98 (2015) 204-210. doi:10.1016/j.supflu.2014.12.015. 
[6] X. Wang, X. Liang, J. Li, Q. Li, Catalytic hydrogenolysis of biomass-derived 5hydroxymethylfurfural to biofuel 2,5-dimethylfuran, Appl. Catal. A Gen. (2019) 8595. doi:10.1016/j.apcata.2019.03.005.

[7] M. Brzezińska, N. Keller, A.Ruppert, Self-tuned properties of CuZnO catalysts for hydroxymethylfurfural hydrodeoxygenation towards dimethylfuran production, Catal. Sci. Technol., 10 (2020) 658-670. doi: 10.1039/C9CY01917K

[8] J. Chen, Y. Ge, Y. Guo, J. Chen, Selective hydrogenation of biomass-derived 5hydroxymethylfurfural using palladium catalyst supported on mesoporous graphitic carbon nitride, J. Energy Chem. 27 (2018) 283-289. doi:10.1016/j.jechem.2017.04.017.

[9] S. Lima, D. Chadwick, K. Hellgardt, Towards sustainable hydrogenation of 5(hydroxymethyl)furfural: A two-stage continuous process in aqueous media over RANEY® catalysts, RSC Adv. 7 (2017) 31404-31407. doi:10.1039/c7ra03318d.

[10] G. Berndes, J. Hansson, Bioenergy expansion in the EU: Cost-effective climate change mitigation, employment creation and reduced dependency on imported fuels, Energy Policy. (2007). doi:10.1016/j.enpol.2007.08.003.

[11] I. Delidovich, P.J.C. Hausoul, L. Deng, R. Pfützenreuter, M. Rose, R. Palkovits, Alternative Monomers Based on Lignocellulose and Their Use for Polymer Production, Chem. Rev. 116 (2016) 1540-1599. doi:10.1021/acs.chemrev.5b00354.

[12] T. Buntara, S. Noel, P.H. Phua, I. Melián-Cabrera, J.G. De Vries, H.J. Heeres, Caprolactam from renewable resources: Catalytic conversion of 5hydroxymethylfurfural into caprolactone, Angew. Chemie - Int. Ed. 50 (2011) 70837087. doi:10.1002/anie.201102156. 
[13] M.S. Gyngazova, L. Negahdar, L.C. Blumenthal, R. Palkovits, Experimental and kinetic analysis of the liquid phase hydrodeoxygenation of 5-hydroxymethylfurfural to 2,5-dimethylfuran over carbon-supported nickel catalysts, Chem. Eng. Sci. 173 (2017) 455-464. doi:10.1016/j.ces.2017.07.045.

[14] S. Fulignati, C. Antonetti, D. Licursi, M. Pieraccioni, E. Wilbers, H.-J. Heeres, A. M. Raspolli Galletti, Insight into the hydrogenation of pure and crude HMF to furan diols using $\mathrm{Ru} / \mathrm{C}$ as catalyst, Appl. Catal. A, Gen. 578 (2019) 122-133. doi: 10.1016/j.apcata.2019.04.007

[15] P. Priecel, N. Azam Endot, P. Demma Carà, J.A. Lopez-Sanchez, Fast Catalytic Hydrogenation of 2,5-Hydroxymethylfurfural to 2,5-Dimethylfuran with Ruthenium on Carbon Nanotubes, Ind. Eng. Chem. Res. 57(6) (2018) 1991-2002, doi: 10.1021/acs.iecr.7b04715

[16] B. Ledesma, J. Juárez, J. Mazarío, M. Domine, A. Beltramone, Bimetallic platinum/iridium modified mesoporous catalysts applied in the hydrogenation of HMF, Catal. Today, (2019). doi : 10.1016/j.cattod.2019.06.037

[17] N. Ly, K. Al-Shamery, C. E. Chan-Thaw, L. Prati, P. Carniti, A. Gervasini, Impact of Support Oxide Acidity in Pt-Catalyzed HMF Hydrogenation in Alcoholic Medium, Catal. Lett., 147 (2017) 345-359. doi: 10.1007/s10562-016-1945-9

[18] J. Luo, H. Yun, A. V. Mironenko, K. A. Goulas, J. D. Lee, M. Monai, C. Wang, V. Vorotnikov, C. B. Murray, D. G. Vlachos, P. Fornasiero, R. J. Gorte, Mechanisms for High Selectivity in the Hydrodeoxygenation of 5-Hydroxymethylfurfural over PtCo Nanocrystals, ACS Catal., 6(7) (2016) 4095-4104. doi: 10.1021/acscatal.6b00750

[19] S. Cattaneo, H. Naslhajian, F. Somodi, C. Evangelisti, A. Villa, L. Prati, Ruthenium on Carbonaceous Materials for the Selective Hydrogenation of HMF, Molecules 23(8) (2018) 2007-2019. doi: 10.3390/molecules23082007 
[20] A. Iriondo, A. Mendiguren, M.B. Güemez, J. Requies, J.F. Cambra, 2,5-DMF production through hydrogenation of real and synthetic 5-HMF over transition metal catalysts supported on carriers with different nature, Catalysis Today 279 (2017) 286295. doi: 10.1016/j.cattod.2016.02.019

[21] R. Šivec, M. Grilc, M. Huš, B. Likozar, Multiscale Modeling of (Hemi)cellulose Hydrolysis and Cascade Hydrotreatment of 5-Hydroxymethylfurfural, Furfural, and Levulinic Acid, Industrial \& Engineering Chemistry Research, 58(35) (2019) 1601816032. doi: 10.1021/acs.iecr.9b00898

[22] T. Birsa Čelič, M. Grilc, B. Likozar, N. Novak Tušar, In situ Generation of Ni Nanoparticles from Metal-Organic Framework Precursors and Their Use for Biomass Hydrodeoxygenation, ChemSusChem 8(10) (2015) 1703-1710. doi: $10.1002 /$ cssc. 201403300

[23] K. Kohli, R. Prajapati, B.K. Sharma, Bio-based chemicals from renewable biomass for integrated biorefineries, Energies. 12 (2019). doi:10.3390/en12020233.

[24] X. Kong, Y. Zhu, H. Zheng, F. Dong, Y. Zhu, Y.W. Li, Switchable synthesis of 2,5dimethylfuran and 2,5-dihydroxymethyltetrahydrofuran from 5-hydroxymethylfurfural over Raney Ni catalyst, RSC Adv. 4 (2014) 60467-60472. doi:10.1039/c4ra09550b.

[25] S. Lima, D. Chadwick, K. Hellgardt, Towards sustainable hydrogenation of 5(hydroxymethyl)furfural: a two-stage continuous process in aqueous media over RANEY® catalysts, RSC Adv., 7 (2017) 31401-31407. doi: 10.1039/C7RA03318D

[26] X. Kong, R. Zheng, Y. Zhu, G. Ding, Y. Zhu, Y.-W. Li, Rational design of Ni-based catalysts derived from hydrotalcite for selective hydrogenation of 5hydroxymethylfurfural, Green Chem., 17 (2015) 2504-2514. doi: 
[27] S. Srivastava, G.C. Jadeja, J. Parikh, Synergism studies on alumina-supported coppernickel catalysts towards furfural and 5-hydroxymethylfurfural hydrogenation, J. Mol. Catal. A: Chemical 426 (2017) 244-256. doi: 10.1016/j.molcata.2016.11.023

[28] N. Siddiqui, A.S. Roy, R. Goyal, R. Khatun, C. Pendem, A.N. Chokkapu, A. Bordoloi, R. Bal, Hydrogenation of 5-hydroxymethylfurfural to 2,5-dimethylfuran over nickel supported tungsten oxide nanostructured catalyst, Sustain. Energy Fuels. 2 (2018) 191-198. doi:10.1039/c7se00363c.

[29] B. Seemala, C.M. Cai, C.E. Wyman, P. Christopher, Support Induced Control of Surface Composition in $\mathrm{Cu}-\mathrm{Ni} / \mathrm{TiO}_{2}$ Catalysts Enables High Yield Co-Conversion of HMF and Furfural to Methylated Furans, ACS Catal. 7 (2017) 4070-4082. doi:10.1021/acscatal.7b01095.

[30] R. Goyal, B. Sarkar, A. Bag, N. Siddiqui, D. Dumbre, N. Lucas, S.K. Bhargava, A. Bordoloi, Studies of synergy between metal-support interfaces and selective hydrogenation of HMF to DMF in water, J. Catal. (2016). doi:10.1016/j.jcat.2016.05.012.

[31] C. Zhu, Q. Liu, D. Li, H. Wang, C. Zhang, C. Cui, L. Chen, C. Cai, L. Ma, Selective Hydrodeoxygenation of 5-Hydroxymethylfurfural to 2,5-Dimethylfuran over $\mathrm{Ni}$ Supported on Zirconium Phosphate Catalysts, ACS Omega. 3 (2018) 7407-7417. doi:10.1021/acsomega.8b00609.

[32] L.C. Chen, S.D. Lin, The ethanol steam reforming over $\mathrm{Cu}-\mathrm{Ni} / \mathrm{SiO} 2$ catalysts: Effect of $\mathrm{Cu} / \mathrm{Ni}$ ratio, Appl. Catal. B Environ. (2011). doi:10.1016/j.apcatb.2011.06.028.

[33] A.R. Naghash, T.H. Etsell, S. Xu, XRD and XPS study of Cu-Ni interactions on reduced copper-nickel-aluminum oxide solid solution catalysts, Chem. Mater. 18 (2006) 2480-2488. doi:10.1021/cm051910o. 
[34] A.M. Ruppert, J. Grams, M. Jędrzejczyk, J. Matras-Michalska, N. Keller, K. Ostojska, P. Sautet, Titania-Supported Catalysts for Levulinic Acid Hydrogenation: Influence of Support and its Impact on $\gamma$-Valerolactone Yield, ChemSusChem. 8 (2015) 1538-1547. doi:10.1002/cssc.201403332.

[35] R. Chen, Y. Du, Xing Weihong, Xu Nanping, The Effect of Titania Structure on $\mathrm{Ni} / \mathrm{TiO}_{2}$ Catalysts for p-Nitrophenol Hydrogenation, 14 (2006) 665-669. doi:10.1016/S1004-9541(06)60132-8.

[36] K.J.A. Raj, M.G. Prakash, R. Mahalakshmy, T. Elangovan, B. Viswanathan, Selective hydrogenation of acetophenone over nickel supported on titania, Catal. Sci. Technol. 2 (2012) 1429-1436. doi:10.1039/c2cy20134h.

[37] M. Lafjah, A. Mayoufi, E. Schaal, F. Djafri, N. Keller, V. Keller, $\mathrm{TiO}_{2}$ nanorods for gas phase photocatalytic applications, Catal. Today. 235 (2014) 193-200. doi:10.1016/j.cattod.2014.03.015.

[38] B.T. Kasuga, M. Hiramatsu, A. Hoson, T. Sekino, K. Niihara, Titania Nanotubes Prepared by Chemical Processing, Adv. Mater. 11 (1999) 1307-1311.

[39] D. V. Bavykin, J.M. Friedrich, F.C. Walsh, Protonated Titanates and $\mathrm{TiO}_{2}$ Nanostructured Materials : Synthesis, Properties, and Applications, Adv. Mater. 18 (2006) 2807-2824. doi:10.1002/adma.200502696.

[40] M. Grandcolas, L. Sinault, F. Mosset, A. Louvet, N. Keller, V. Keller, Selfdecontaminating layer-by-layer functionalized textiles based on $\mathrm{WO}_{3}$-modified titanate nanotubes. Application to the solar photocatalytic removal of chemical warfare agents, Appl. Catal. A Gen. 391 (2011) 455-467. doi:10.1016/j.apcata.2010.05.028.

[41] M. Grandcolas, T. Cottineau, A. Louvet, N. Keller, V. Keller, Solar light-activated 
photocatalytic degradation of gas phase diethylsulfide on $\mathrm{WO}_{3}$-modified $\mathrm{TiO}_{2}$ nanotubes, Appl. Catal. B Environ. 138-139 (2013) 128-140. doi:10.1016/j.apcatb.2013.02.041.

[42] B. Erjavec, R. Kaplan, P. Djinović, A. Pintar, Catalytic wet air oxidation of bisphenol A model solution in a trickle-bed reactor over titanate nanotube-based catalysts, Appl. Catal. B Environ. 132-133 (2013) 342-352. doi:10.1016/j.apcatb.2012.12.007.

[43] G.H. Du, Q. Chen, R.. Che, Z.Y. Yuan, L.M. Peng, Preparation and structure analysis of titanium oxide nanotubes, App. Phys. Lett. 3702 (2001) 3702. doi:10.1063/1.1423403.

[44] H. Ou, S. Lo, Review of titania nanotubes synthesized via the hydrothermal treatment : Fabrication , modification, and application, Purif. Meth. 58 (2007) 179-191. doi:10.1016/j.seppur.2007.07.017.

[45] T. Beuvier, M. Richard-Plouet, M.M.-L. Granvalet, T. Brousse, O. Crosnier, L. Brohan, $\mathrm{TiO}_{2}$ (B) Nanoribbons As Negative Electrode Material for Lithium Ion Batteries with High Rate Performance, Inorg. Chem. 49 (2010) 8457-8464. doi:10.1021/ic1010192.

[46] D.L. Morgan, H.-Y. Zhu, R.L. Frost, E.R. Waclawik, Determination of a Morphological Phase Diagram of Titania / Titanate Nanostructures from Alkaline Hydrothermal Treatment of Degussa P25, Chem. Mater. 20 (2008) 3800-3802. doi:10.1021/cm800077e.

[47] H. Liu, Z. Bi, X. Sun, R.R. Unocic, M.P. Paranthaman, S. Dai, G.M. Brown, Mesoporous $\mathrm{TiO}_{2}-\mathrm{B}$ Microspheres with Superior Rate Performance for Lithium Ion Batteries, Adv. Mater. 23 (2011) 3450-3454. doi:10.1002/adma.201100599. 
[48] T.P. Feist, D. Peter, The Soft Chemical Synthesis of $\mathrm{TiO}_{2}(\mathrm{~B})$ from Layered Titanates, J. Solid State Chem. 101 (1992) 275-295. doi:10.1016/0022-4596(92)90184-W.

[49] R. Grosjean, M. Fehse, S. Pigeot-Remy, L. Stievano, L. Monconduit, S. Cassaignon, Facile synthetic route towards nanostructured $\mathrm{Fe}-\mathrm{TiO}_{2}(\mathrm{~B})$, used as negative electrode for Li-ion batteries, J. Power Sources. 278 (2015) 1-8. doi:10.1016/j.jpowsour.2014.12.032.

[50] J. Xiong, J. Chen, J. Zhang, Liquid-phase hydrogenation of o-chloronitrobenzene over supported nickel catalysts, Catal. Commun. 8 (2007) 345-350. doi:10.1016/j.catcom.2006.06.028.

[51] W. Huo, C. Zhang, H. Yuan, M. Jia, C. Ning, Y. Tang, Vapor-phase selective hydrogenation of maleic anhydride to succinic anhydride over $\mathrm{Ni} / \mathrm{TiO}_{2}$ catalysts, J. Ind. Eng. Chem. 20 (2014) 4140-4145. doi:10.1016/j.jiec.2014.01.012.

[52] S.W. Ho, C.Y. Chu, S.G. Chen, Effect of thermal treatment on the nickel state and CO hydrogenation activity of titania-supported nickel catalysts, J. Catal. 178 (1998) 34-48. doi:10.1006/jcat.1998.2102.

[53] Y. Lin, Y. Zhu, X. Pan, X. Bao, Modulating the methanation activity of Ni by the crystal phase of $\mathrm{TiO}_{2}$, Catal. Sci. Technol. 7 (2017) 2813-2818. doi:10.1039/c7cy00124j.

[54] D.A. Peña, B.S. Uphade, P.G. Smirniotis, TiO2-supported metal oxide catalysts for low-temperature selective catalytic reduction of $\mathrm{NO}$ with $\mathrm{NH}_{3}$ : I. Evaluation and characterization of first row transition metals, J. Catal. 221 (2004) 421-431. doi:10.1016/j.jcat.2003.09.003.

[55] J. Scaranto, S. Giorgianni, A quantum-mechanical study of $\mathrm{CO}$ adsorbed on $\mathrm{TiO}_{2}$ : A 
comparison of the Lewis acidity of the rutile ( $\left(\begin{array}{lll}1 & 1 & 0\end{array}\right)$ and the anatase $\left(\begin{array}{lll}1 & 0 & 1\end{array}\right)$ surfaces, J. Mol. Struct. THEOCHEM. 858 (2008) 72-76. doi:10.1016/j.theochem.2008.02.027.

[56] A.M. Ruppert, J. Grams, J. Matras-Michalska, M. Chełmicka, P. Przybysz, ToF-SIMS study of the surface of catalysts used in biomass valorization, Surf. Interface Anal. 46 (2014) 726-730. doi:10.1002/sia.5370.

[57] L. Kubelková, J. Nováková, N.I. Jaeger, G. Schulz-Ekloff, Characterization of nickel species at $\mathrm{Ni} / \gamma-\mathrm{Al}_{2} \mathrm{O}_{3}$ and $\mathrm{Ni} /$ faujasite catalysts by carbon monoxide adsorption, Appl. Catal. A Gen. 95 (1993) 87-101. doi:10.1016/0926-860X(93)80199-Z.

[58] S. Derrouiche, D. Bianchi, Heats of adsorption of the linear and bridged CO species on a Ni/ $/ \mathrm{Al}_{2} \mathrm{O}_{3}$ catalyst by using the AEIR method, Appl. Catal. A Gen. 313 (2006) 208217. doi:10.1016/j.apcata.2006.07.025.

[59] X. Zhu, P. Huo, Y. P. Zhang, D. G. Cheng, C. J. Liu, Structure and reactivity of plasma treated $\mathrm{Ni} / \mathrm{Al}_{2} \mathrm{O}_{3}$ catalyst for $\mathrm{CO}_{2}$ reforming of methane, Appl. Catal. B Environ. 81 (2008) 132-140. doi:10.1016/j.apcatb.2007.11.042.

[60] K. Hadjiivanov, H. Knözinger, M. Mihaylov, FTIR study of CO adsorption on NiZSM-5, J. Phys. Chem. B. 106 (2002) 2618-2624. doi:10.1021/jp0132782.

[61] J.T. Yates, C. Garland, Infrared Studies of Carbon Monooxide Chemisorbed on Mercury-Poisoned Nickel Surfaces, J. Phys. Chem. 65 (1961) 617-624. doi:10.1021/j100822a007.

[62] C.W. Garland, R.C. Lord, P.F. Troiano, Infrared spectrum of carbon monoxide chemisorbed on evaporated nickel films, J. Phys. Chem. 69 (1965) 1195-1203. doi:10.1021/j100888a017.

[63] X. Zhu, Y.P. Zhang, C.J. Liu, CO adsorbed infrared spectroscopy study of $\mathrm{Ni} / \mathrm{Al}_{2} \mathrm{O}_{3}$ 
catalyst for $\mathrm{CO}_{2}$ reforming of methane, Catal. Letters. 118 (2007) 306-312. doi:10.1007/s10562-007-9205-7.

[64] M. Mihaylov, K. Hadjiivanov, H. Knözinger, Formation of $\mathrm{Ni}(\mathrm{CO})_{4}$ during the interaction between $\mathrm{CO}$ and silica-supported nickel catalyst: An FTIR spectroscopic study, Catal. Letters. 76 (2001) 59-63. doi:10.1023/A:1016786023456.

[65] M. Chidambarama, A. T. Bell, A two-step approach for the catalytic conversion of glucose to 2,5-dimethylfuran in ionic liquids, Green Chem., 12 (2010) 1253-1262. doi: $10.1039 / \mathrm{C} 004343 \mathrm{E}$

[66] A.M. Ruppert, M. Jẹdrzejczyk, N. Potrzebowska, K. Kaźmierczak, M. Brzezińska, O. Sneka-Płatek, P. Sautet, N. Keller, C. Michel, J. Grams, Supported gold-nickel nanoalloy as a highly efficient catalyst in levulinic acid hydrogenation with formic acid as an internal hydrogen source, Catal. Sci. Technol. 8 (2018) 4318-4331. doi:10.1039/c8cy00462e.

[67] M. Zieliński, R. Wojcieszak, S. Monteverdi, M. Mercy, M.M. Bettahar, Hydrogen storage on nickel catalysts supported on amorphous activated carbon, Catal. Commun. 6 (2005) 777-783. doi:10.1016/j.catcom.2005.07.001.

[68] V. V. Pushkarev, N. Musselwhite, K. An, S. Alayoglu, G.A. Somorjai, High Structure Sensitivity of Vapor-Phase Furfural Decarbonylation/Hydrogenation Reaction Network as a Function of Size and Shape of Pt Nanoparticles, Nano Lett. 12 (2012) 5196-5201. doi:10.1021/n13023127. 